\title{
Biomarkers of progression to oral cancer in patients with dysplasia: A systematic review
}

\author{
CÉSAR RIVERA $^{1}$, ROCÍO GALLEGOS ${ }^{2}$ and CONSTANZA FIGUEROA ${ }^{2}$ \\ ${ }^{1}$ Department of Stomatology, Oral Medicine Group; ${ }^{2}$ School of Dentistry, Faculty of Health Sciences, \\ University of Talca, North Campus, Talca, Maule Region 3460000, Chile
}

Received April 18, 2019; Accepted March 31, 2020

DOI: $10.3892 / \mathrm{mco} .2020 .2112$

\begin{abstract}
Identifying oral dysplastic lesions with a high risk of malignant transformation may create opportunities for early therapeutic interventions. Several tissue biomarkers have been suggested to date as prognostic indicators of the progression of dysplastic lesions to oral cancer. We herein present a systematic review (PROSPERO CRD42018086476), with the aim of identifying, evaluating and summarizing evidence on prognostic biomarkers of progression to oral cancer in patients with dysplasia. A search through MEDLINE/PubMed and Scopus databases was performed. The review only included primary articles that reported risk values associated with malignancy after a multivariate analysis. The quality of the findings was analyzed using the Reporting Recommendations for Tumor Marker Prognostic Studies, and research trends were established using SciCurve Open. A total of 4 potential biomarkers were identified: Degree of dysplasia, and the proteins retinal dehydrogenase 1, prominin-1 and podoplanin. All 3 protein biomarkers have been recognized as cancer stem cell markers. The studies were of acceptable quality, although none included sample size determinations. Due to the lack of validation and follow-up studies, these biomarkers are considered to be in a discovery phase and require validation by prospective clinical trials. The present analysis indicated that there are currently insufficient data to include these biomarkers in the clinical decision-making process.
\end{abstract}

\section{Introduction}

Oral cancer development is a multi-step process, in which the malignancy is preceded by a susceptible epithelium $(1,2)$. In general, histological diagnosis of oral epithelial dysplasia is considered as the most important indicator for the risk of

Correspondence to: Dr César Rivera, Department of Stomatology, Oral Medicine Group, University of Talca, S/N, Office 8, North Campus, Lircay Av., Talca, Maule Region 3460000, Chile

E-mail: cerivera@utalca.cl

Key words: oral dysplasia, tumorigenic transformation, oral cancer, biomarkers, neoplasm proteins progression to oral cancer (3). Oral epithelial dysplasia refers to the chronic and progressive histopathological alterations that result in premalignant transformation of the oral mucosa. In the oral cavity, dysplasia manifests as a series of clinical and histological variations that may include leukoplakia, erythroplakia, or the combination of the two (4). However, the literature also reports that this is a subjective diagnosis, with both inter- and intra-examiner variations in diagnostic criteria (5). The increase in the degree of dysplasia (from mild to moderate to severe) has been associated with a high rate of progression to cancer, with the rates ranging from 6 to $36 \%$ (6). In addition, some dysplastic lesions may remain clinically unchanged, or even exhibit complete regression $(3,6)$.

The identification of oral dysplastic lesions with a high risk of transformation to oral cancer remains a clinical challenge, which, if resolved, would allow patients to benefit from early interventions. According to the cancer dictionary (https://www.cancer.gov/publications/dictionaries/cancer-terms/ def/transformation), 'transformation' designates the changes that a normal cell undergoes as it becomes malignant. When these changes become visible (such as potentially malignant lesions and macroscopic cancer), it indicates that the cell has undergone a long process that includes subtle molecular alterations, which are the true and most meaningful changes in terms of malignant transformation.

There are currently no biomarkers (defined as molecules or characteristics used as indicators of a biological state) that are routinely used in the clinical setting to predict high-risk oral dysplastic lesions. Taking into account that several biomarkers have been suggested as predictors of the malignant transformation of oral dysplasia, a systematic review was conducted, which is widely accepted as the 'gold standard' in evidence-based medicine (7). The objective of the review was to identify, evaluate and summarize the currently available evidence on biomarkers of progression to oral cancer in patients diagnosed with dysplasia.

Only articles that reported risk values from multivariate analysis (binary logistic regression or Cox proportional hazards models) were selected. After filtering the results, high-grade epithelial dysplasia and three proteins, namely retinal dehydrogenase 1 (ALDH1A1), prominin-1 (PROM1) and podoplanin (PDPN), were determined as risk factors for malignant transformation. 


\section{Materials and methods}

Study design. A systematic review was conducted. The independent variables were the prognostic biomarkers; the dependent variable was malignant transformation from a dysplastic state to oral cancer. A well-defined protocol was created. This protocol was imported into the International Prospective Register of Systematic Reviews (PROSPERO), which includes health records, under the code: CRD42018086476. These steps were undertaken to minimize the risk of bias.

Prognostic biomarker. A prognostic biomarker was defined as a molecule or histological characteristic obtained from a study that involved a binary logistic regression analysis or a Cox proportional hazards model. To be included in the present review, articles must have demonstrated a significant association between oral dysplasia biomarkers and malignant transformation (8). The computed risk, odds ratio (OR) or hazard ratio (HR), should have been reported as the risk of progression to oral cancer from the biomarker group vs. the reference group, with $\mathrm{OR} / \mathrm{HR}>1$ indicating increased risk and $\mathrm{OR} / \mathrm{HR}<1$ indicating decreased risk (9).

Search strategy. A systematic search was conducted through MEDLINE/PubMed and Scopus databases for all literature published in English up to January 18, 2018. The search was conducted using the following keyword combinations: Oral dysplasia [Title/Abstract] or leukoplakia [Title/Abstract] or erythroplakia [Title/Abstract] AND biomarkers [MeSH Terms] AND risk [Title/Abstract] or risk ratio [Title/ Abstract] or relative risk [Title/Abstract] or odds ratio [Title/Abstract] AND human [MeSH Terms] AND English [Language]. All selected studies were original researches evaluating biomarkers of progression to oral cancer in patients diagnosed with epithelial dysplasia.

Inclusion and exclusion criteria. Articles were included based on previously published protocols $(9,10)$. Briefly, we selected studies that investigated biomarkers with an impact on malignant transformation, which were subjected to multivariate analysis and presented the possibility of constructing the study groups. Articles that did not include oral dysplasia, leukoplakia or erythroplakia and risk terms in their titles, abstracts or keywords, studies not carried out on humans and non-primary researches, were excluded. Additionally, articles that did not report risk values, those with unclear definition criteria for groups and variables, and those with errors in statistical information, were also excluded.

Data extraction. Titles and abstracts were imported into Rayyan online application (https://rayyan.qcri.org) (11) and they were analyzed independently by two trained reviewers. Discrepancies were resolved by consensus. Biomarker names, experimental design, statistical method, sample size, risk values, $\mathrm{P}$-values and confidence intervals were extracted from the selected articles.

Quality assessment. Quality assessment was performed in duplicate using Reporting Recommendations for Tumor Marker Prognostic Studies (REMARK) (12). The evaluators' agreement level was assessed by Kappa analysis.
Scientific output trends. To determine the most extensively studied biomarkers, SciCurve Open was used. SciCurve Open is a search engine that transforms a systematic review into a comprehensible environment (9).

\section{Results}

Most biomarkers are proteins evaluated by immunohistochemistry. A total of 80 articles (Data S1, https://doi. org/10.5281/zenodo.2574148) were identified, of which a duplicate and 67 that did not meet the eligibility criteria were excluded. A total of 13 studies were subjected to full-text review, of which 9 articles were excluded due to the impossibility of constructing groups of interest, i.e., cases and controls expressing different levels of the biomarker associated with the history of malignant transformation. Finally, 4 articles that met the inclusion criteria were retrieved $(6,13-15)$. The PRISMA flow chart is shown in Fig. 1.

The descriptive aspects of each study were extracted. This information is summarized in Table I. Four articles evaluated 4 biomarkers in convenience samples collected between 1978 and 2010. All studies had a retrospective design, mostly evaluating proteins by immunohistochemistry. We herein present the main conclusions of each investigation and the number of citations it received (up to November 2018).

Malignant transformation appears to be the result of a high biomarker expression. Oral lesions with high expression of biomarkers presented a higher risk for malignant transformation (Table II). Variable cohort sizes were used, ranging from 34 to 141 patients. A total of 10 covariables were incorporated into 4 multivariate analyses. The variables most frequently used in adjustments were proteins ( 3 models) and smoking habit ( 2 models). However, none were found to be statistically significantly associated with malignant transformation. Therefore, the reported biomarkers may be considered as independent prognostic markers. Of these, degree of dysplasia, ALDH1A1 and PROM1 stand out. These markers were evaluated in investigations that included a greater number of subjects and presented smaller confidence intervals. Due to the heterogeneity of the studies, a meta-analysis was not performed.

Studies do not report how the sample size was determined. The researchers' agreement level was 0.86 , which is classified as almost optimal. Differences were resolved by consensus. According to the REMARK analysis, the studies are of high quality (they met $>15$ criteria). However, none of the studies reported how sample size and biological effect were established, or how missing data were handled. These aspects are relevant for biomarker validation. More details may be found in Data S1, (https://doi.org/10.5281/zenodo.2574148).

PDPN is the most extensively researched protein. To identify the research trends relating to proposed protein biomarkers, biomedical information in the SciCurve Open online tool was explored. SciCurve uses PubMed to generate graphs and curves that help to reveal trends in the literature (16), which allows for the identification of publications, citations, authors and the most prolific countries conducting research in a given 


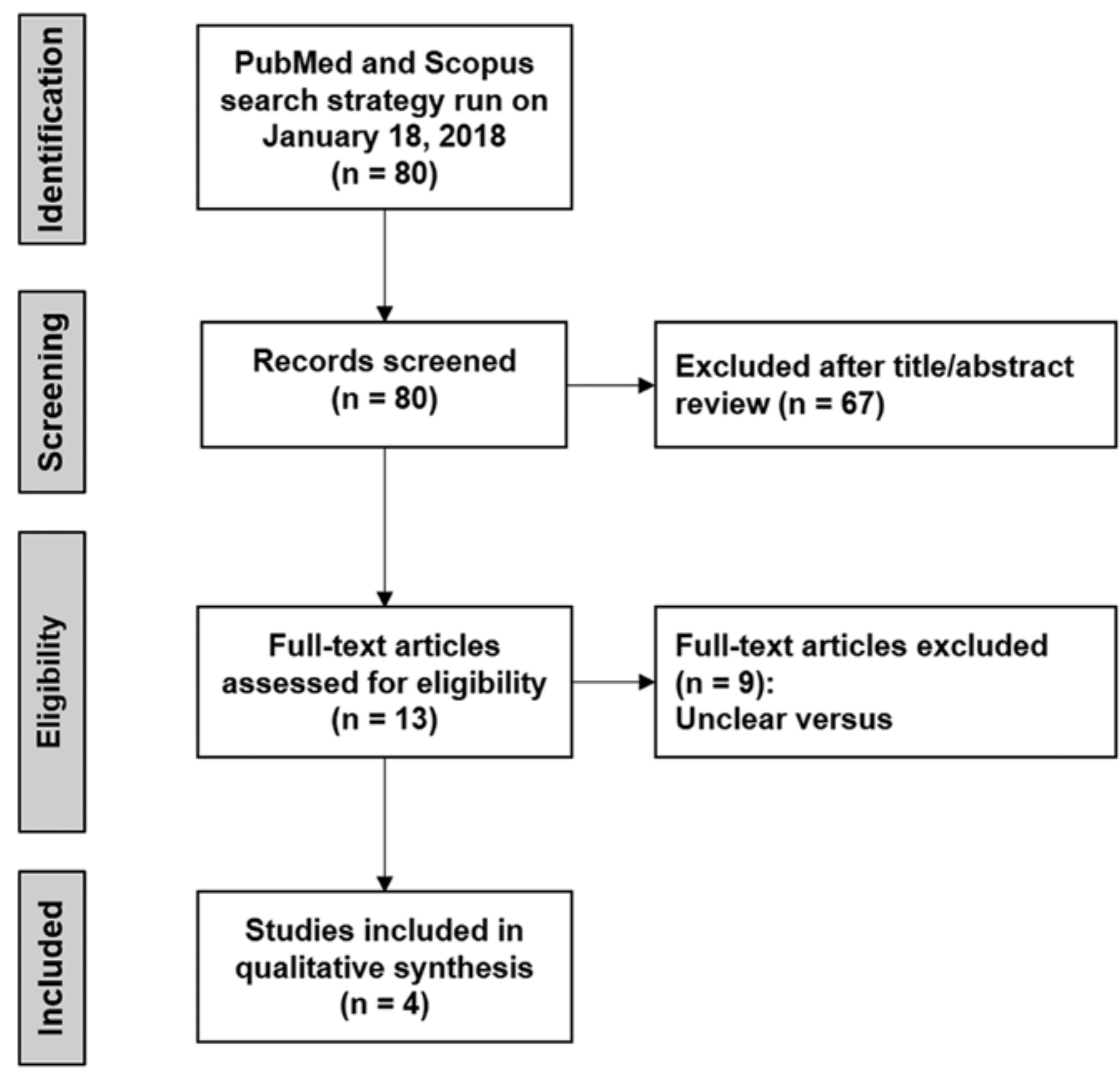

Figure 1. PRISMA diagram. Flow representing systematic search on biomarkers in oral dysplastic lesions. Unclear versus, unclear defining criteria for groups and variables.

area, among factors. As shown in Fig. 2, PDPN is the most extensively investigated biomarker in oral epithelial dysplasia, as well as in oral cancer.

\section{Discussion}

Biomarkers are currently a field of particular interest, as they may prove helpful in resolving diagnostic challenges. In the future, they may enable personalized diagnoses and guide early therapeutic interventions. Oral epithelial dysplasia is considered as the most important prognostic indicator for determining the risk of malignant transformation of lesions that have this potential (17). However, histopathology is limited in its ability to predict the cancerization of these epithelial lesions (18). In this systematic review, only 4 potential biomarkers that could support more precise determinations of clinical risk were identified: The degree of dysplasia and 3 proteins recognized as cancer stem cell markers.

The 'natural history' of oral cancer allows for the study of different phases in malignant progression (19). It is well understood that a susceptible oral epithelium may be represented by the typical architectural changes of oral epithelial dysplasia. This transformation starts and progresses through several steps, from hyperplasia and dysplasia (mild, moderate and severe) to carcinoma in situ and invasive cancer.

Two of the studies included in the present review demonstrated that patients with advanced or high-risk dysplasia are 2-5 times more likely to develop oral cancer $(6,15)$. This finding has also been reported in other types of cancer. For example, the presence of dysplasia is the gold standard biomarker for cancer risk in Barrett's esophagus (20). In the context of cervical cancer, women with high-grade cervical dysplasia (referred to as intraepithelial neoplasia) have a higher risk of malignancy $(21,22)$. In terms of therapy, a systematic review concluded that the surgical removal of lesions displaying severe epithelial dysplasia significantly reduced the progression to cancer. Untreated lesions had a risk of malignant transformation $(\sim 39 \%)$ that was 6 times higher compared with that of treated lesions $(\sim 8 \%)(23)$. These results emphasize that the degree of epithelial dysplasia is useful for determining the potential for progression to oral cancer, justifying surgical removal of high-grade lesions and continuous monitoring. Similarly, we believe that the degree of oral epithelial dysplasia should be included in multivariate models that study any lesion aspect.

Studies have demonstrated that an early diagnosis (24) and a short interval from diagnosis to treatment are associated with high survival rates (25). As carcinogenesis is progressive, studying the beginning may provide more clinical opportunities (2). The onset may be represented by an epithelium displaying mild dysplasia (since severe lesions are a precursor to cancer). Identifying the alterations occurring in the epithelium beyond architectural changes may enable us to recognize which lesion will evolve. It is likely that, in this context, oral carcinogenesis starts with the transformation of a limited number of keratinocytes (1). A large number of proteins with diverse normal functions are involved in human cancer, and identifying them may help elucidate the clinical course of oral epithelial dysplasia. In the context of this research, these proteins are referred to as 'biomarkers'. We selected a total of 
Table I. All included studies are retrospective.

\begin{tabular}{|c|c|c|c|c|c|c|}
\hline Study, year & Biomarker & Change & Design & Research remarks & Citations & (Refs.) \\
\hline \multicolumn{7}{|l|}{$\begin{array}{l}\text { Insensitivity to } \\
\text { anti-growth signals }\end{array}$} \\
\hline Feng et al, 2013 & ALDH1A $1^{\mathrm{a}}$ & $(+)$ & $\begin{array}{l}\text { Retrospective } \\
(1993-2009) \\
\text { IHC } \\
\text { China }\end{array}$ & $\begin{array}{l}\text { ALDH1A1 expression was } \\
\text { found to be significantly } \\
\text { associated with increased risk of } \\
\text { transformation }\end{array}$ & 32 & (13) \\
\hline Liu et al, 2013 & $\begin{array}{l}\text { ALDH1A } 1^{\mathrm{a}} \\
\text { PROM1 }^{\mathrm{a}}\end{array}$ & $\begin{array}{l}(+) \\
(+)\end{array}$ & $\begin{array}{l}\text { Retrospective } \\
(1978-2008) \\
\text { IHC } \\
\text { China }\end{array}$ & $\begin{array}{l}\text { ALDH1A1 and PROM1 were } \\
\text { correlated with malignant } \\
\text { transformation in patients with } \\
\text { premalignant oral leukoplakia }\end{array}$ & 50 & $(15)$ \\
\hline \multicolumn{7}{|l|}{$\begin{array}{l}\text { Tissue invasion and } \\
\text { metastasis }\end{array}$} \\
\hline de Vicente et al, 2013 & $\mathrm{PDPN}^{\mathrm{a}}$ & $(+)$ & $\begin{array}{l}\text { Retrospective } \\
(2000-2005) \\
\text { IHC } \\
\text { Spain }\end{array}$ & $\begin{array}{l}\text { May be a valuable biomarker for } \\
\text { risk assessment of malignant } \\
\text { transformation in patients with } \\
\text { oral leukoplakia along with } \\
\text { histological assessment }\end{array}$ & 50 & (14) \\
\hline \multicolumn{7}{|l|}{$\begin{array}{l}\text { Histopathological } \\
\text { characteristics }\end{array}$} \\
\hline Kaur et al, 2014 & $\begin{array}{l}\text { Dysplasia } \\
\text { (grade) }\end{array}$ & $(+)$ & $\begin{array}{l}\text { Retrospective } \\
(2000-2010) \\
\text { Histopathology } \\
\text { Canada }\end{array}$ & $\begin{array}{l}\text { Degree of dysplasia emerged as } \\
\text { an independent factor for identi } \\
\text { fying high-risk dysplasia }\end{array}$ & 38 & (6) \\
\hline Liu et al, 2013 & $\begin{array}{l}\text { Dysplasia } \\
\text { (grade) }\end{array}$ & $(+)$ & $\begin{array}{l}\text { Retrospective } \\
(1978-2008) \\
\text { Histopathology } \\
\text { China }\end{array}$ & $\begin{array}{l}\text { Grade of dysplasia was } \\
\text { significantly associated with } \\
\text { increased risk of malignant } \\
\text { transformation }\end{array}$ & 50 & (15) \\
\hline
\end{tabular}

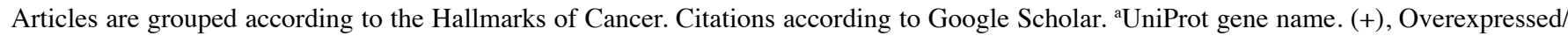
highly expressed; IHC, immunohistochemistry; ALDH1A1, retinal dehydrogenase 1; POM1, prominin-1; PDPN, podoplanin.

4 studies that described multivariate analyses for 3 proteins analyzed by immunohistochemistry: ALDH1A1, PROM1 and PDPN. The high expression of these proteins was associated with malignant transformation of dysplastic lesions.

ALDH1A1 activity can define normal tissue stem cells and cancer stem cell populations, where it is involved in self-renewal, differentiation and self-protection (26). High ALDH1A1 activity and overexpression are associated with poor prognosis of lung (27), esophageal (28) and breast cancers (29). Accumulating evidence suggests that ALDH1A1 may represent a useful therapeutic cancer stem cell target in tissues that do not normally express high levels of ALDH1A1 (26). Considering that this protein is not present at high levels in the oral mucosa (30), ALDH1A1 may represent a therapeutic opportunity for preventing the progression to oral cancer in patients with dysplasia.

The precise physiological function of PROM1 is unclear, but its ubiquitous presence indicates its relevance (31). PROM1, a membrane glycoprotein, is widely used for identifying stem cells in various normal tissues and cancer stem cells. This protein is a key regulator ensuring appropriate response of stem cells to extracellular signals (32). Its usefulness for cancer stem cells appears to be extremely important, as by inhibiting PROM1, the signaling pathways that are involved in angiogenesis and cell proliferation will also be inhibited (31).

PDPN is a transmembrane glycoprotein considered to be a specific marker for lymphatic endothelial cells (33). However, PDPN is not restricted to endothelial cells, its expression also being detected in epithelial basal cells of the oral mucosa (34). Populations of cancer stem cells expressing PDPN has high clonal expansion rates, which helps establish squamous cell carcinomas (35). PDPN has also been shown to promote cancer cell clonal capacity, migration, epithelial-to-mesenchymal transition, invasion, metastasis and inflammation (33). According to our results, PDPN has been the most widely investigated biomarker over the last 20 years, in both oral dysplasias and oral cancer. However, publication and citation numbers reveal that research has tended to focus more on the end of progression, which is cancer. We believe that this trend should be reversed, and that analyses should be focused on lesions that have not yet progressed to oral cancer, as this would give a more preventive character to biomedical efforts.

All reported protein biomarkers are associated with populations of stem cells in cancer. Cumulatively, the studies 
Table II. High expression of biomarkers constitutes a risk for malignant transformation (dysplasia to oral cancer).

\begin{tabular}{|c|c|c|c|c|c|c|c|c|}
\hline Study, year & Biomarker $^{\mathrm{a}}$ & $\begin{array}{l}\text { Clinical } \\
\text { diagnosis }^{\mathrm{b}}\end{array}$ & $\mathrm{N}$ & $\begin{array}{c}\text { Cases vs. reference } \\
\text { (events/group) }\end{array}$ & HR & $\mathrm{CI}$ & P-value & (Refs.) \\
\hline \multicolumn{9}{|l|}{$\begin{array}{l}\text { Insensitivity to } \\
\text { anti-growth signals }\end{array}$} \\
\hline Feng et al, 2013 & ALDH1A1 & $\begin{array}{l}\text { Oral } \\
\text { erythroplakia }\end{array}$ & 34 & $\begin{array}{l}\text { Positive (14/19) vs. } \\
\text { negative }(3 / 15)\end{array}$ & $8.9^{c}$ & $1.7-47.4$ & 0.011 & (13) \\
\hline \multirow[t]{2}{*}{ Liu et al, 2013} & ALDH1A1 & $\begin{array}{l}\text { Oral } \\
\text { leukoplakia }\end{array}$ & 141 & $\begin{array}{l}\text { Positive }(26 / 54) \text { vs. } \\
\text { negative }(11 / 76)\end{array}$ & 4.2 & $2.0-8.9$ & $<0.001$ & $(15)$ \\
\hline & PROM1 & & 141 & $\begin{array}{l}\text { Positive (19/32) vs. } \\
\text { negative }(18 / 109)\end{array}$ & 2.9 & $1.5-5.6$ & 0.002 & \\
\hline \multicolumn{9}{|l|}{$\begin{array}{l}\text { Tissue invasion and } \\
\text { metastasis }\end{array}$} \\
\hline de Vicente et al, 2013 & PDPN & $\begin{array}{l}\text { Oral } \\
\text { leukoplakia }\end{array}$ & 58 & $\begin{array}{l}\text { Score } 2-3(11 / 22) \text { vs. } \\
0-1(2 / 36)\end{array}$ & 8.7 & $1.8-41.6$ & 0.007 & (14) \\
\hline \multicolumn{9}{|l|}{$\begin{array}{l}\text { Histopathological } \\
\text { characteristics }\end{array}$} \\
\hline \multirow[t]{2}{*}{ Kaur et al, 2014} & Dysplasia & $\begin{array}{l}\text { Oral lesions } \\
\text { with }\end{array}$ & 97 & $\begin{array}{l}\text { Moderate }(18 / 39) \text { vs. } \\
\text { mild }(12 / 58)\end{array}$ & 2.5 & $1.6-10.8$ & 0.013 & (6) \\
\hline & Dysplasia & dysplasia & 71 & $\begin{array}{l}\text { Severe }(9 / 13) \text { vs. } \\
\text { mild }(12 / 58)\end{array}$ & 5.4 & $2.6-23.2$ & $<0.001$ & \\
\hline Liu et al, 2013 & Dysplasia & $\begin{array}{l}\text { Oral } \\
\text { leukoplakia }\end{array}$ & 141 & $\begin{array}{l}\text { High-grade (13/32) vs. } \\
\text { low-grade }(24 / 109)\end{array}$ & 2.4 & $1.2-4.8$ & 0.018 & $(15)$ \\
\hline
\end{tabular}

Articles are grouped according to the Hallmarks of Cancer. ${ }^{a}$ Gene name. ${ }^{b}$ All clinical diagnoses are accompanied by epithelial dysplasia as histopathological diagnosis. ${ }^{\circ}$ Odds ratio (logistic regression). Diagnosis, risk, CI and P-values are reported as they appear in the included articles. N, number of compared subjects; HR, hazard ratio; CI, confidence interval; ALDH1 A1, retinal dehydrogenase 1; POM1, prominin-1; PDPN, podoplanin.

A

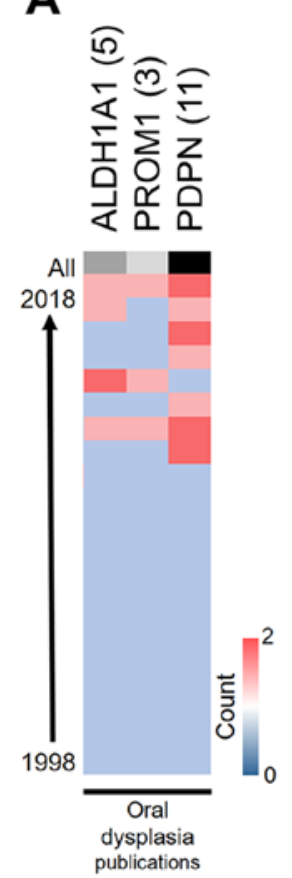

vs.

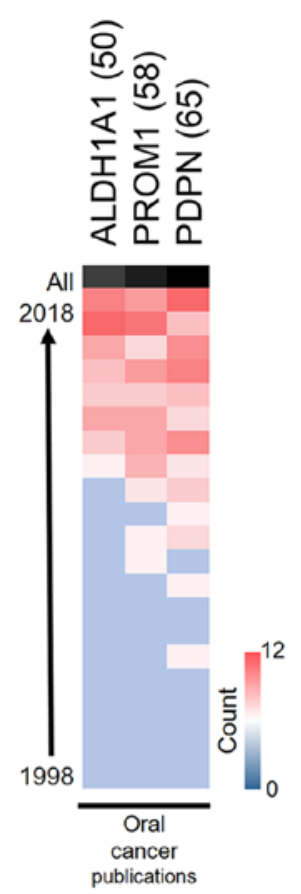

B

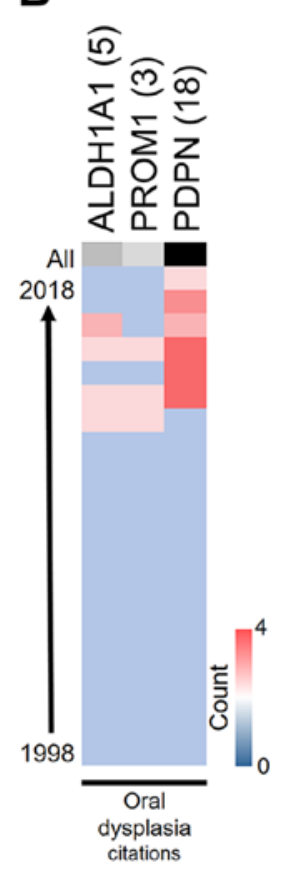

VS.

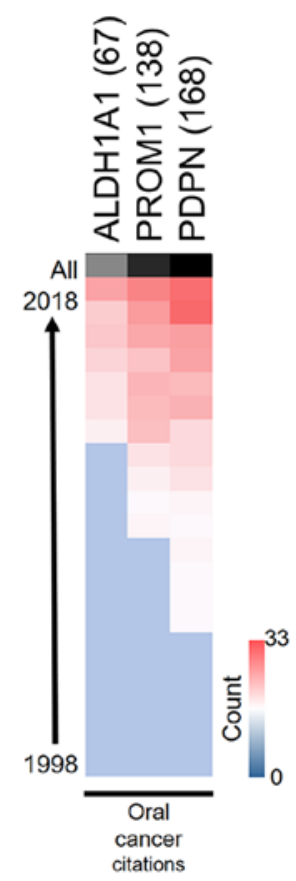

Figure 2. Research trends in protein biomarkers of malignant progression from dysplasia to oral cancer. (A) PDPN is the most widely investigated protein in dysplasia (11 publications) and in oral cancer (65 publications) over the last 20 years. It must be emphasized that the study of these markers has been more focused on oral cancer rather than on premalignant histological stages. (B) Citations associated with the proposed proteins. The trends are also led by PDPN. PDPN, podoplanin; ALDH1A1, retinal dehydrogenase 1; PROM1, prominin-1. 
we have considered support the role of cancer stem cells in promoting tumor progression from a dysplastic state. Two recent articles highlight the fact that that potentially malignant disorders of the oral mucosa expressing markers of cancer stem cells are at high risk of evolving into oral cancer $(36,37)$.

We previously performed a systematic review to identify published prognostic oral cancer biomarkers (9). In that investigation, we evaluated cancer biomarkers associated with common clinical endpoints: Overall survival, disease-free survival and cause-specific survival. In that context, ALDH1A1, PROM1 and PDPN were identified as potential prognostic biomarkers for disease-free survival, indicating that these proteins are important for malignant transformation as well as for the absence of signs of disease after treatment.

Oral cancer is generally considered as a preventable disease, as smoking and drinking habits are reported in the majority of the patients, and exerting a synergistic effect (38). However, there is an increasing number of non-smoking, non-drinking patients, both male and female, who develop oral cancers that are currently not considered preventable (39). Surprisingly, none of the selected articles reported a statistical association of these and other factors (such as age, sex, oral subsite and previous oral cancer) with oral malignant transformation. Recognizing the importance of these clinical variables, we believe that the results of multivariate models should be interpreted with caution.

The selected articles were critically analyzed according to the REMARK guidelines. None of the studies included information on sample size determination or data loss management. This is a clear limitation of the present study, since an appropriate sample enables more efficient and reliable investigations. The absence of sample calculations also limits result interpretations (40) The increasing availability and use of predictive models to facilitate clinical decision-making highlights the need for a careful evaluation of the validity of these models (41). The development of biomarkers involves multiple processes, linking initial discovery in basic studies, validation, and clinical implementation (42). Accordingly, the reported biomarkers must be placed in the discovery phase, since they must now undergo a necessary validation process to determine their true value in the clinical setting.

In the present review, few biomarkers that may explain the progression from epithelial dysplasia to oral cancer were identified. The currently available literature states that advanced or high-grade epithelial dysplasia determines the need for lesion removal. To the best of our knowledge, the main contribution of a set of immunohistochemical biomarkers may be at earlier dysplastic stages. The use of a complete panel that reveals the presence of cancer stem cells may prove fundamental to the early recognition of oral cancer. The present systematic review used strict statistical criteria for article inclusion. The findings were based on 4 studies, which is rather insufficient to draw any definitive conclusions, and these findings must be validated through further research. Studies on protein variability in a large number of patients and tissues are also recommended.

\section{Acknowledgements}

Not applicable.

\section{Funding}

No funding was received.

\section{Availability of data and materials}

All datasets generated and/or analyzed during the present study are included in this published article.

\section{Authors' contributions}

CR conceived the study and was in charge of overall direction and planning. $\mathrm{CR}, \mathrm{RG}$ and $\mathrm{CF}$ conducted the systematic review, including the design and drafting of the manuscript. $\mathrm{CR}$ verified the data extracted following the literature search. $\mathrm{CR}, \mathrm{RG}$ and $\mathrm{CF}$ were responsible for proofreading and critically revising the review for intellectual content. All authors have read and approved the final version of the manuscript.

\section{Ethics approval and consent to participate}

Not applicable.

\section{Patient consent for publication}

Not applicable.

\section{Competing interests}

All the authors declare that they have no competing interests.

\section{References}

1. Rivera C: Essentials of oral cancer. Int J Clin Exp Pathol 8: 11884-11894, 2015.

2. Rivera C: The challenge of the state of susceptibility to oral cancer. J Oral Res 4: 8-9, 2015.

3. van der Waal I: Potentially malignant disorders of the oral and oropharyngeal mucosa; terminology, classification and present concepts of management. Oral Oncol 45: 317-323, 2009.

4. Mohajertehran F and Sahebkar A: The promise of stem cell markers in the diagnosis and therapy of epithelial dysplasia and oral squamous cell carcinoma. J Cell Physiol 233: 8499-8507, 2018.

5. Ranganathan K and Kavitha L: Oral epithelial dysplasia: Classifications and clinical relevance in risk assessment of oral potentially malignant disorders. J Oral Maxillofac Pathol 23: 19-27, 2019.

6. Kaur J, Matta A, Kak I, Srivastava G, Assi J, Leong I, Witterick I, Colgan TJ, Macmillan C, Siu KW, et al: S100A7 overexpression is a predictive marker for high risk of malignant transformation in oral dysplasia. Int J Cancer 134: 1379-1388, 2014.

7. Stern C, Munn Z, Porritt K, Lockwood C, Peters MDJ, Bellman S, Stephenson $\mathrm{M}$ and Jordan Z: An international educational training course for conducting systematic reviews in health care: The Joanna Briggs Institute's Comprehensive Systematic Review Training Program. Worldviews Evid Based Nurs 15: 401-408, 2018.

8. Ballman KV: Biomarker: Predictive or prognostic? J Clin Oncol 33: 3968-3971, 2015.

9. Rivera C, Oliveira AK, Costa RAP, De Rossi T and Paes Leme AF: Prognostic biomarkers in oral squamous cell carcinoma: A systematic review. Oral Oncol 72: 38-47, 2017.

10. Mallett S, Timmer A, Sauerbrei W and Altman DG: Reporting of prognostic studies of tumour markers: A review of published articles in relation to REMARK guidelines. Br J Cancer 102: 173-180, 2010.

11. Ouzzani M, Hammady H, Fedorowicz Z and Elmagarmid A: Rayyan-a web and mobile app for systematic reviews. Syst Rev 5: 210,2016 
12. Altman DG, McShane LM, Sauerbrei W and Taube SE: Reporting recommendations for tumor marker prognostic studies (REMARK): Explanation and elaboration. PLoS Med 9: e1001216, 2012.

13. Feng JQ, Xu ZY, Shi LJ, Wu L, Liu W and Zhou ZT: Expression of cancer stem cell markers ALDH1 and Bmil in oral erythroplakia and the risk of oral cancer. J Oral Pathol Med 42: 148-153, 2013.

14. de Vicente JC, Rodrigo JP, Rodriguez-Santamarta T, Lequerica-Fernandez P, Allonca E and Garcia-Pedrero JM: Podoplanin expression in oral leukoplakia: Tumorigenic role. Oral Oncol 49: 598-603, 2013.

15. Liu W, Wu L, Shen XM, Shi LJ, Zhang CP, Xu LQ and Zhou ZT: Expression patterns of cancer stem cell markers ALDH1 and CD133 correlate with a high risk of malignant transformation of oral leukoplakia. Int J Cancer 132: 868-874, 2013.

16. Connected Researchers. SciCurve: Revealing life science's curves, 2014. Available from: http://connectedresearchers. com/tag/scicurve/. Accessed November 16, 2018.

17. Liu W, Wang YF, Zhou HW, Shi P, Zhou ZT and Tang GY: Malignant transformation of oral leukoplakia: A retrospective cohort study of 218 Chinese patients. BMC Cancer 10: 685, 2010

18. Taxy JB: Pathology of head and neck neoplasms. UptoDate (online). Waltham, MA: UpToDate Inc. 2018 [cited 2018 10/25] Available from: https://www.uptodate.com/contents/pathology-o f-head-and-neck-neoplasms.

19. Rivera C: Opportunities for biomarkers with potential clinical use in oral cancer. Medwave 15: e6186, 2015 (In English, Spanish).

20. Dunbar KB and Souza RF: Beyond dysplasia grade: The role of biomarkers in stratifying risk. Gastrointest Endosc Clin N Am 27: 447-459, 2017.

21. Rebolj M, Helmerhorst T, Habbema D, Looman C, Boer R, van Rosmalen J and van Ballegooijen M: Risk of cervical cancer after completed post-treatment follow-up of cervical intraepithelial neoplasia: Population based cohort study. BMJ 345: e6855, 2012.

22. McCredie MR, Sharples KJ, Paul C, Baranyai J, Medley G, Jones RW and Skegg DC: Natural history of cervical neoplasia and risk of invasive cancer in women with cervical intraepithelial neoplasia 3: A retrospective cohort study. Lancet Oncol 9: 425-434, 2008

23. Zhang L, Lubpairee T, Laronde DM and Rosin MP: Should severe epithelial dysplasia be treated? Oral Oncol 60: 125-129, 2016.

24. Dissanayaka WL, Pitiyage G, Kumarasiri PV, Liyanage RL, Dias KD and Tilakaratne WM: Clinical and histopathologic parameters in survival of oral squamous cell carcinoma. Oral Surg Oral Med Oral Pathol Oral Radiol 113: 518-525, 2012.

25. Tsai WC, Kung PT, Wang YH, Huang KH and Liu SA: Influence of time interval from diagnosis to treatment on survival for oral cavity cancer: A nationwide cohort study. PLoS One 12: e0175148, 2017.

26. Tomita H, Tanaka K, Tanaka T and Hara A: Aldehyde dehydrogenase 1A1 in stem cells and cancer. Oncotarget 7: 11018-11032, 2016.

27. Li X, Wan L, Geng J, Wu CL and Bai X: Aldehyde dehydrogenase $1 \mathrm{~A} 1$ possesses stem-like properties and predicts lung cancer patient outcome. J Thorac Oncol 7: 1235-1245, 2012.

28. Yang L, Ren Y, Yu X, Qian F, Bian BS, Xiao HL, Wang WG, Xu SL, Yang J, Cui W, et al: ALDH1A1 defines invasive cancer stem-like cells and predicts poor prognosis in patients with esophageal squamous cell carcinoma. Mod Pathol 27: 775-783, 2014.
29. Morimoto K, Kim SJ, Tanei T, Shimazu K, Tanji Y, Taguchi T, Tamaki Y, Terada N and Noguchi S: Stem cell marker aldehyde dehydrogenase 1-positive breast cancers are characterized by negative estrogen receptor, positive human epidermal growth factor receptor type 2, and high Ki67 expression. Cancer Sci 100: 1062-1068, 2009.

30. The HumanProtein Atlas. ALDH1A1:Proteinexpressionoverview [cited 2019 accessed 11 January 2019].Available from: https://www. proteinatlas.org/ENSG00000165092-ALDH1A1/tissue.

31. Barzegar Behrooz A, Syahir A and Ahmad S: CD133: Beyond a cancer stem cell biomarker. J Drug Target 27: 257-269, 2019.

32. Singer D, Thamm K, Zhuang H, Karbanová J, Gao Y, Walker JV, Jin $\mathrm{H}, \mathrm{Wu} \mathrm{X}$, Coveney CR, Marangoni $\mathrm{P}$, et al: Prominin-1 controls stem cell activation by orchestrating ciliary dynamics. EMBO J 38: e99845, 2019.

33. Krishnan H, Rayes J, Miyashita T, Ishii G, Retzbach EP, Sheehan SA, Takemoto A, Chang YW, Yoneda K, Asai J, et al: Podoplanin: An emerging cancer biomarker and therapeutic target. Cancer Sci 109: 1292-1299, 2018.

34. Cirligeriu L, Cimpean AM, Raica M and Doros CI: Dual role of podoplanin in oral cancer development. In Vivo 28: 341-347, 2014.

35. Miyashita T, Higuchi Y, Kojima M, Ochiai A and Ishii G: Single cell time-lapse analysis reveals that podoplanin enhances cell survival and colony formation capacity of squamous cell carcinoma cells. Sci Rep 7: 39971, 2017.

36. Saluja TS, Ali M, Mishra P, Kumar V and Singh SK: Prognostic value of cancer stem cell markers in potentially malignant disorders of oral mucosa: A meta-analysis. Cancer Epidemiol Biomarkers Prev 28: 144-153, 2019.

37. Surendran S, Siddappa G, Mohan A, Hicks W Jr, Jayaprakash V, Mimikos C, Mahri M, Almarzouki F, Morrell K, Ravi R, et al: Cancer stem cell and its niche in malignant progression of oral potentially malignant disorders. Oral Oncol 75: 140-147, 2017.

38. Koontongkaew S: The tumor microenvironment contribution to development, growth, invasion and metastasis of head and neck squamous cell carcinomas. J Cancer 4: 66-83, 2013.

39. Vargas-Ferreira F, Nedel F, Etges A, Gomes AP, Furuse C and Tarquinio SB: Etiologic factors associated with oral squamous cell carcinoma in non-smokers and non-alcoholic drinkers: A brief approach. Braz Dent J 23: 586-590, 2012.

40. Faber J and Fonseca LM: How sample size influences research outcomes. Dental Press J Orthod 19: 27-29, 2014.

41. Taylor JM, Ankerst DP and Andridge RR: Validation of biomarker-based risk prediction models. Clin Cancer Res 14: 5977-5983, 2008

42. Goossens N, Nakagawa S, Sun X and Hoshida Y: Cancer biomarker discovery and validation. Transl Cancer Res 4: 256-269, 2015 